\title{
Study on the Translation of Publicity Materials from the Perspective of Cross Cultural Translation
}

\author{
Xu Lei ${ }^{1, ~ a ~}$, Huang $\mathrm{He}^{2, ~ b}$ \\ 1,2 Jiangxi Institute of Economic Administrators, Nanchang, Jiangxi, 330088 China \\ a 694934089 @qq.com, b85606299@qq.com
}

Keywords: publicity materials; translation; cross-culture; pragmatics; strategies

\begin{abstract}
As important media of language and culture communication, publicity materials not only are featured with cross-linguistics, but also with cross-culture and cross-border from the perspective of the role. The translation even provides an approach for the whole world to know about China. As a result, the correct and proper translation of publicity materials has a great significance. In this paper, the author began with cross-cultural pragmatics and basic concept of publicity materials translation and elaborated the relations between cross-cultural pragmatics and the translation of publicity materials.
\end{abstract}

\section{Introduction}

With the technical progress and economic development in China, the comprehensive national strength and international competitiveness of China are increasingly improving. Publicity materials are considered as the important approach for other countries to know about China and have a significant influence on spreading standpoints and political views of China, enhancing international competitiveness and improving culture soft power in China. The cross-cultural pragmatics is the combination of language and culture and mainly studies the characteristics of language behaviors in the cross-cultural communication process, thus the cross-cultural pragmatics has the extremely important guiding role in the translation of publicity materials. In the process of translation, we will be so affected by politics, culture, economy and environment that we can't accurately translate publicity materials. As translators, we must improve translation accuracy and accurately grasp the cultural and habit differences between China and foreign countries before translation. As a result, the cross-cultural pragmatic theory plays an important role in the process of the translation of publicity materials. Not only can it improve translation efficiency, but also can publicize cultural transition in China, enhance international status of China, and display the cultural containment.

\section{The Translation Strategy of publicity materials from the Cross-cultural Pragmatic Perspective}

\subsection{Grasp the linguistic difference and carefully consider the contents of publicity materials} translation

The translation of publicity materials gets involved in the exchange between different cultures, which will inevitably have a language difference. Therefore, as conducting the translation of publicity materials under the cross-cultural pragmatic perspective, on the one hand, it is necessary to accurately grasp the language difference under the different cultural backgrounds, analyze the transformation rule between different languages, fully grasp the different language expressions and try to avoid using the Chinese language expression. On the other hand, it must accurately comprehend the significance expressed in Chinese and refer to the translation object thinking to restate Chinese, ensuring the translation accuracy and rationality. 


\subsection{Completely comprehend cultural difference and carry forward the traditional Chinese culture}

The translation of publicity materials is the exchange and collision between different cultures, thus translation is closely related to the culture. On the one hand, the process of translation means that we must comprehensively understand the difference of diverse cultures, including national history, value, custom and religious belief. The cultural difference should be selectively retained and transformed. On the other hand, in the process of translation, translators should notice the transpositional consideration and consider problems from the perspective of readers. In this way, translation will be accepted by readers. In addition, the translation of publicity materials is an effective approach for the world to know about China. Therefore, the translation of publicity materials should notice the good international image of China and pay attention to carrying forward and develop the excellent Chinese culture, so that the world will know more about Chinese culture.

\subsection{Consider the social difference and enhancer readability of publicity materials}

Chinese and western cultural concepts have a great difference, so the social environment and cultural background in China and west have a larger difference. In the translation of publicity materials, it is necessary to notice the social environment and cultural background of target readers. In this way, it can enhance the readability of publicity-oriented materials. For example, as translating some vocabularies or sentences with the bright political standpoints, it must combine with the social environment and cultural background, so as to affect the translation effects of publicity materials. As translating the vocabularies or sentences with Chinese characteristics, it must consider translation readability and intelligibility. If it is not easy to understand by literal translation, an elucidative manner can be used for translation.

\subsection{Grasp translation skills and skillfully dispose of different publicity materials}

It is necessary to firmly master some translation skills for publicity materials translation based on the different cultural backgrounds. In the process of the translation of publicity materials, it will inevitably translate different literary forms, such as newspapers, magazine news, press conferences and government notice. Different texts have different features. The translation of publicity materials must combine with the types of translation materials, select the suitable translation methods and strategies, notice the translation effects, consider original intention, and skillfully increase and transform, so that it is convenient for readers to comprehend and accept and reach the excellent effects of the translation of publicity materials

The translation of publicity materials measures under the cross-cultural pragmatics are shown as follows:

(1) Translation of newspapers: At present, the influence of newspapers in the global reports is still obvious. The cultural embodiment in newspapers is very abundant. In the process of the publicity materials translation, it is necessary to analyze the cultural features and news points in the newspapers. Translation is formed through the equivalent translation to analyze the cultural elements of newspapers and promote accurate news translation.

(2) Translation of news magazines: News magazines use the inheritance manner to conduct the cultural recording. They will be changed as time flies. The report contents of news magazines are relatively profound and meticulous. Moreover, news magazines are strongly integrated with the culture. Translators must base on their own opinions and value comprehension to give overall considerations to the foreign traditional culture and language element to ensure accurate translation.

(3) Translation of advertising texts: The main effect of advertising texts is to express the purpose. Through induction and publication, audiences can understand the contents to be conveyed. The advertising translation doesn't mean to just translate advertising text. Instead, it is necessary to have the in-depth comprehension on the cultural difference in advertising and ensure that the core advertising meaning can be accurately translated and achieve the goal of propaganda. In the process of translating commercial advertisement, it must understand the native language culture and aesthetics and ensure the spreading effects of advertising. 
(4) Translation of the press conference: The publicity materials of the general press conference belong to the text language, showing the extensive integrated information. Generally speaking, it has no subjective opinions, but just states the fact objectively. As a result, when translating the publicity materials in the press conference, it must comprehend the native language style and thought. Under the precondition of conforming to the readers' etiquette, it must accurately display the national benefits and accurately translate publicity materials. If publicity materials include political factors and military factors, translators should consider the national benefits as the primary translation principle, consider overseas cultural difference, and conduct the accurate translation by catering to the audiences' reading demands.

\section{Tab. 1 Terms in Common Use}

\begin{tabular}{|c|c|}
\hline Word-word translation & $\begin{array}{l}\text { Translation for external propaganda; } \\
\text { Translation for foreign propaganda }\end{array}$ \\
\hline Emphasis on internationality & $\begin{array}{l}\text { C-E translation for international publicity; } \\
\text { C-E translation for global communication; } \\
\text { Translation for China's international communication; } \\
\text { Translation for China’s global communication }\end{array}$ \\
\hline Emphasis on target receiver & $\begin{array}{l}\text { Foreign-oriented publicity translation; } \\
\text { Overseas-targeted publicity translation; } \\
\text { Publicity-oriented C/E translation; } \\
\text { External publicity translation; } \\
\text { International publicity translation. } \\
\end{array}$ \\
\hline Emphasis on material & Translation of materials for international publicity. \\
\hline
\end{tabular}

Tab. 2 Documentary translations

\begin{tabular}{|c|c|c|c|c|}
\hline $\begin{array}{l}\text { Function of } \\
\text { translation }\end{array}$ & \multicolumn{4}{|c|}{ Document of source-· culture communicative interaction for target--culture readership } \\
\hline $\begin{array}{l}\text { Function } \\
\text { target text }\end{array}$ & \multicolumn{4}{|l|}{ Metatextual function } \\
\hline $\begin{array}{ll}\text { Type } & \text { of } \\
\text { translation }\end{array}$ & \multicolumn{4}{|c|}{ Documentary translation } \\
\hline $\begin{array}{ll}\text { Form } & \text { of } \\
\text { translation }\end{array}$ & Interlineal & Literal translation & $\begin{array}{l}\text { Philological } \\
\text { translation }\end{array}$ & $\begin{array}{l}\text { Exoticizing } \\
\text { translation }\end{array}$ \\
\hline $\begin{array}{l}\text { Purpose of } \\
\text { translation }\end{array}$ & $\begin{array}{l}\text { Reproduction of } \\
\text { SL system }\end{array}$ & $\begin{array}{l}\text { Reproduction of SL } \\
\text { form }\end{array}$ & $\begin{array}{l}\text { Reproduction of } \\
\text { SL form + content }\end{array}$ & $\begin{array}{l}\text { Reproduction of SL } \\
\text { form } \\
+ \text { content }+ \text { situation }\end{array}$ \\
\hline $\begin{array}{l}\text { Focus of } \\
\text { translation } \\
\text { process }\end{array}$ & $\begin{array}{l}\text { Structures of SL } \\
\text { lexis + syntax }\end{array}$ & $\begin{array}{l}\text { Lexical units of } \\
\text { source text }\end{array}$ & $\begin{array}{l}\text { Syntactical units } \\
\text { of source text }\end{array}$ & $\begin{array}{l}\text { Textual units of } \\
\text { source text }\end{array}$ \\
\hline Example & $\begin{array}{l}\text { Comparative } \\
\text { linguistics }\end{array}$ & $\begin{array}{l}\text { Quotations in news } \\
\text { texts }\end{array}$ & $\begin{array}{l}\text { Greek and LatiIl } \\
\text { classics }\end{array}$ & $\begin{array}{l}\text { Modem } \\
\text { prose }\end{array}$ \\
\hline
\end{tabular}

Tab. 3 Instrumental translations

\begin{tabular}{|ll|l|l|l|}
\hline $\begin{array}{l}\text { Function of } \\
\text { translation }\end{array}$ & $\begin{array}{l}\text { Instrument for target-culture communicative interaction modeled according to } \\
\text { source-culture communicative interaction }\end{array}$ \\
\hline $\begin{array}{l}\text { Function of } \\
\text { target text }\end{array}$ & Referential/expressive/appellative/phatic function and/or subfunctions \\
\hline $\begin{array}{l}\text { Type } \\
\text { translation }\end{array}$ of & Instrumental translation & Homologous translation \\
\hline $\begin{array}{l}\text { Form of } \\
\text { translation }\end{array}$ & Equifunctional translation & $\begin{array}{l}\text { Heterofunctiolnal } \\
\text { translation }\end{array}$ \\
\hline $\begin{array}{l}\text { Purpose of } \\
\text { translation }\end{array}$ & $\begin{array}{l}\text { Achieve ST functions For } \\
\text { target audience }\end{array}$ & $\begin{array}{l}\text { Achieve similar functions } \\
\text { as ST }\end{array}$ & $\begin{array}{l}\text { Achieve homologous effect } \\
\text { to ST }\end{array}$ \\
\hline $\begin{array}{l}\text { Focus } \\
\text { translation } \\
\text { process }\end{array}$ & Functional units of ST & $\begin{array}{l}\text { Transferable functions of } \\
\text { ST }\end{array}$ & Degree of ST originality \\
\hline Example & Instructions for use & $\begin{array}{l}\text { “Gulliver's Travels” for } \\
\text { children }\end{array}$ & Poetry translated by poet \\
\hline
\end{tabular}




\section{The Application of the Translation Strategies of Publicity Materials from the Cross-cultural Pragmatic Perspective}

\subsection{The effective communication of cultural contexts-free translation}

For contents with special connotations, events or certain cultural significance in the original context, translators must increase and explain translation so as to supplement the vacant contents in the information and express the implied meaning and information. The augmented translation skill generally is applied in the blank situation of target audiences in the cognitive culture caused by the Chinese and western cultural difference. In "soft news" of Hangzhou G20 official website, in order to render the characteristic tourism resources, some sentence expressions may be abundant and vivid and use multiple rhetorical devices. Translation should be understandable and conform to the language customs. This is the new trend of Chinese translation after China has been the world power in today's society.

\subsection{The literal translation under the host-guest principle}

In English, the address is accustomed to be expressed from the small one to the big one. Chinese is the opposite. In the translation of publicity materials, it must refer to the English logics and expressive habits to translate. For workers who engage in the translation of publicity materials, the translation process must target at the foreign language habits to rewrite and adjust translation words and expression sequence and stand out substantial or important information contents so as to provide the beneficial conditions to realize the better foreign propaganda and persuasion effects. By making a comparison on the hard news translation and the original in G20 official website, it can be found that the translation tries to embody the original purpose and contents. The paragraph structure is basically consistent.

\subsection{The rewriting strategy under the cross-cultural background}

The flubdub, polite formula and jargon with obvious slogan should be suitable deleted. Then, rational explanation should be increased, making it conform to the acceptance habits of audiences. In translation, we can suitably reduce the scale and change the virtuality into reality. The reduction skill means to delete some duplicate messages and less significant information in the target information so that audiences can gain the important information in the short time and improve the efficiency of foreign propaganda and persuasion.

\section{Conclusions}

To sum up, in order to make the effective improvement of publicity materials translation, promote economic development in China and enhance the national status in China, it must fully develop the cultural value utility in China and stand out the cultural status in the global culture. In the process of the translation of publicity materials, translators must give the overall consideration of domestic and overseas cultural difference, life habits and value differences, respect the cultural difference, embody cultural inclusion, promote the improvement and accuracy of the foreign propaganda translation effects, effectively set up the good image of China, and maintain the national benefits. The main purpose of the foreign propaganda is to make readers with different cultural backgrounds have a better understanding of China. The translation should fully respect the language habits and cognitive habits of the latter, suitably increase or delete the original information, rearrange the information sequence and structure. In this way, it can confirm the correct logical relation and ensure exchange accuracy and effectiveness. From the specific information processing of publicity materials translation or macroscopic perspective, the semantic logics and coherence in this translation can't be neglected.

\section{Acknowledgements}

Period results of the fund project: "Study on the Translation of Publicity Materials from the 
Perspective of Cross-cultural Translation”, 2015 Humanities and Social Science Research Project of Jiangxi Institutes of Higher Education (Project Code: YY1514)

\section{References}

[1] The Study on the "Chinese Utterance" System Construction of the Foreign Propaganda Translation under the Pragmatic Perspective[J], Journal of Xinyang Normal University (Philosophy and Social Science Version), 2017, 04:2;

[2] Yang Li, the Influences of the Cultural Differences on the Foreign Propaganda Translation[J], Journal of Jilin Institute of Chemical Technology, 2014, 06: 70-72;

[3] Luo Lili, the "Cultural Loss" of Foreign Propaganda Translation in Zhejiang Tourism Industry and Countermeasures[J], Journal of Ningbo University of Technology, 2015, 04: 61-65;

[4] Dan Xiaoyan and Wang Junying, the Disposal Strategy Study of Cultural Information in the Foreign Propaganda Translation[J], Intelligence, 2016, 31: 238-239;

[5] Zhang Jiachen, the Ecological Function in Urban Foreign Propaganda Translation[J], Journal of Changsha University, 2015, 03: 100-102 